\title{
Squamous carcinoma of the lung with osteocartilaginous stroma
}

\author{
PAUl FLANAGAN, AlEX W. MCCRACKEN, AND ROBERT MC P. CROSS \\ From the Royal Air Force Institute of Pathology and Tropical Medicine, Halton, Bucks.
}

SYNOPSIS An instance of a squamous carcinoma of the lung with osteocartilaginous metaplasia in the stroma is reported. This unusual stromal response is similar to extraskeletal osteocartilaginous metaplasia in any other site, and is a change which occasionally is produced by a variety of pathological and experimental conditions, including gastrointestinal adenocarcinoma and urinary tract epithelial carcinoma. This stromal response should be differentiated from a true sarcomatous participation in the tumour.

\section{CASE REPORT}

The patient, a 46-year-old white man, first complained of right upper chest pain in November 1962. Over the next two months, the pain persisted. He developed a chronic cough, malaise, and lost 10 pounds in weight. He had smoked 20 cigarettes a day for 24 years. In late January, a chest radiograph showed a large left-sided mass, and bronchoscopy revealed a large tumour filling the left main bronchus. At thoracotomy, the tumour was found to occupy the whole of the left upper lobe, breaking through the pleura anteriorly and superiorly. Histological examination of a biopsy specimen was reported as 'showing a mixture of squamous carcinoma and osteogenic sarcoma'. No resection of the tumour was attempted.

Clubbing of the fingers appeared in March. The mass continued to grow and was palpable above the clavicle by the middle of March. A left pleural effusion formed which did not recur after thoracentesis. The patient received $10.5 \mathrm{~g}$. of cyclophosphamide beginning on 4 April. In late April, 4,012 rads of deep $x$-ray therapy were given.

$\mathrm{He}$ became increasingly weak and died on 4 July after four hours of unconsciousness, dyspnoea, and cyanosis.

\section{NECROPSY}

There was well-developed clubbing of the fingers. A large lobulated spheroidal tumour, $15 \mathrm{~cm}$. in diameter, filled the left hemithorax, compressing the lung downward and backward, invading the pleura and obliterating the pleural space. The tumour also invaded the mediastinum and pericardium, displacing these structures to the right. On dissection,

Received for publication 1 December 1964. the tumour appeared to arise from the anterior wall of the left main bronchus, occluding the lumen just before the bifurcation. The cut surface of the tumour was mottled yellowish-white in appearance. In some areas the tumour was hard and gritty (Fig. 1) while in others it was soft and friable. There were multiple areas of bronchopneumonia throughout the right lung. There was a serosanguinous pericardial effusion and a fibrinous pericarditis. Naked-eye examination did not show any metastases. The appearances of other organs, including the central nervous system, were normal.

\section{HISTOLOGICAL EXAMINATION}

The viable portions of the tumour presented various patterns of squamous cell carcinoma within a variable connective tissue stroma (Fig. 2).

In most fields, exuberant fibroblastic growth occurred together with islets of undifferentiated carcinoma (Fig. 3). Certain foci of fibroblasts displayed large rounded nuclei and, occasionally, prominent nucleoli; their fibrils merged into an eosinophilic homogenous matrix (Fig. 4); patches of this matrix stained basophilically, suggesting osteoid, and contained calcium in many foci. Adjacent areas contained a mixture of poorly formed cartilage and woven bone (Fig. 5).

There were many areas with a more mature tissue pattern. Here prickle cells were found within a welldifferentiated squamous cell carcinoma, while cornification and squamous pearls were prominent, and tumour mitoses were lacking. The connective tissue stroma was mature. The fibroblasts were small with dense chromatin. Collagen fibres were plentiful. 


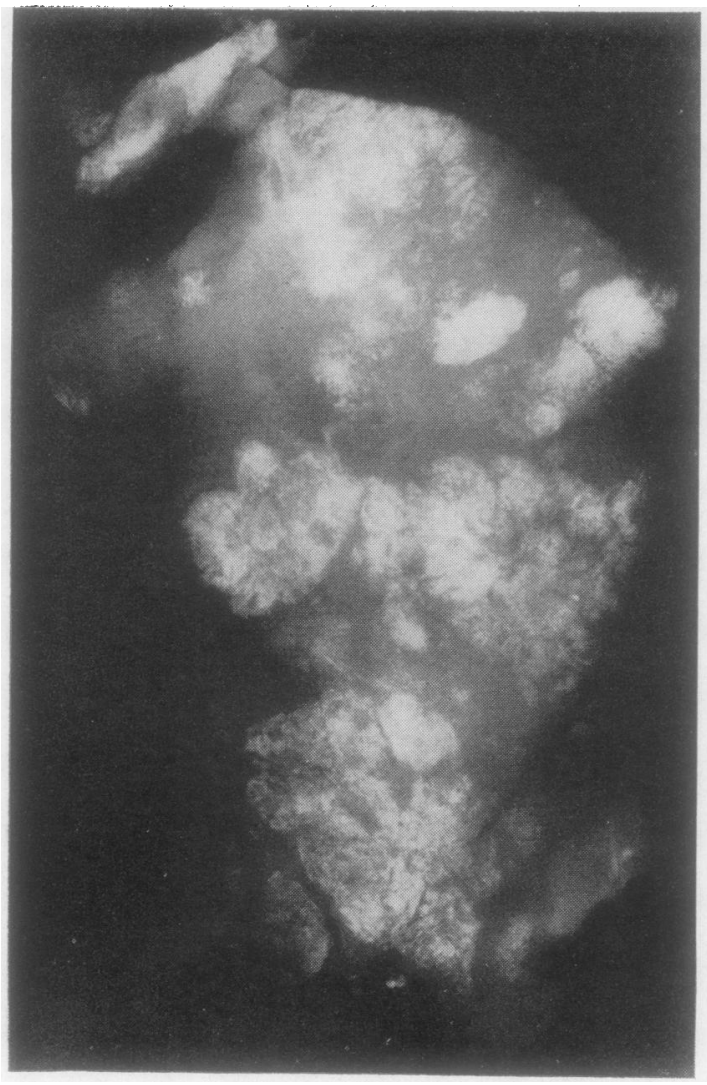

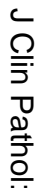

FIG 1. Post-mortem radiograph of a slice through left lung tumour. Note the distribution of fine calcification it? nodules $\times \frac{1}{2}$.

FIG 2. In the lower left corner is a mass of well-differen⿳亠口冋. tiated squamous cells, while in the centre a vascular space is plugged by poorly differentiated squamous cell car ${ }^{\circ}$ cinoma. Note the progressive differentiation from loosen fibroblastic tissue into cartilage with calcification. Haema toxylin and eosin $\times 88$.

FIG. 1 .

FIG. 2 .

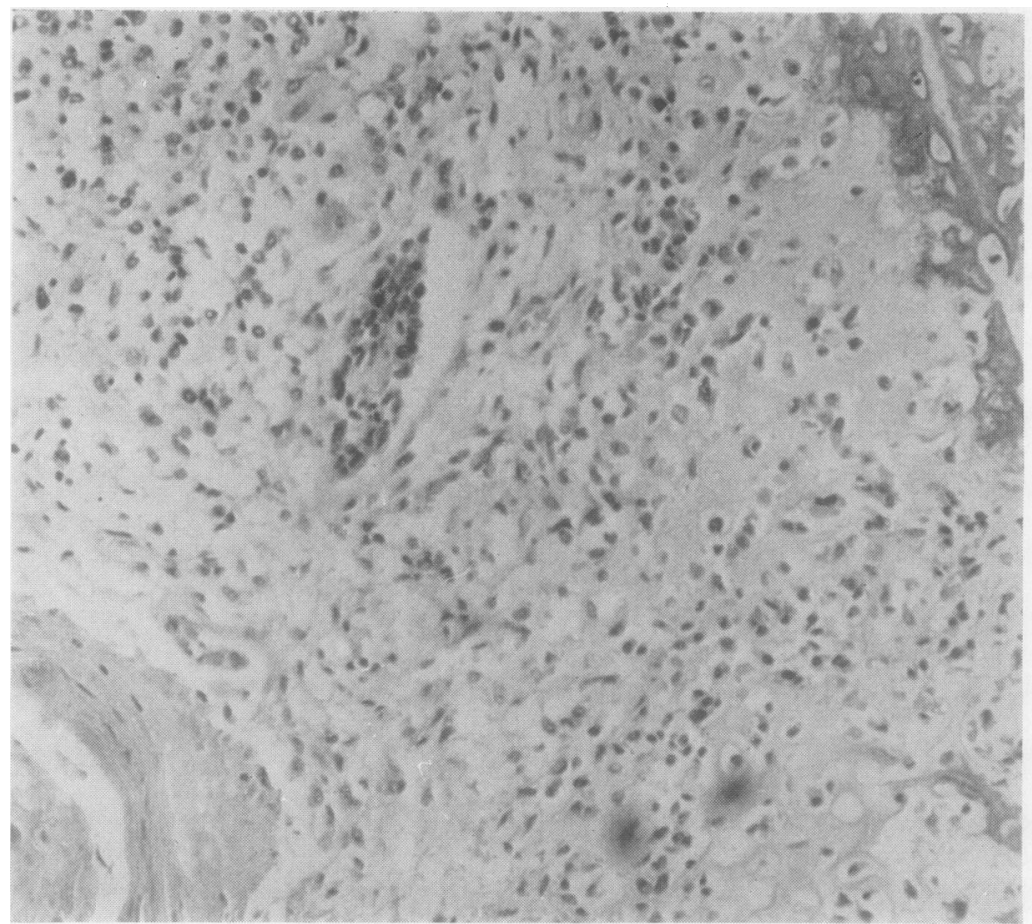




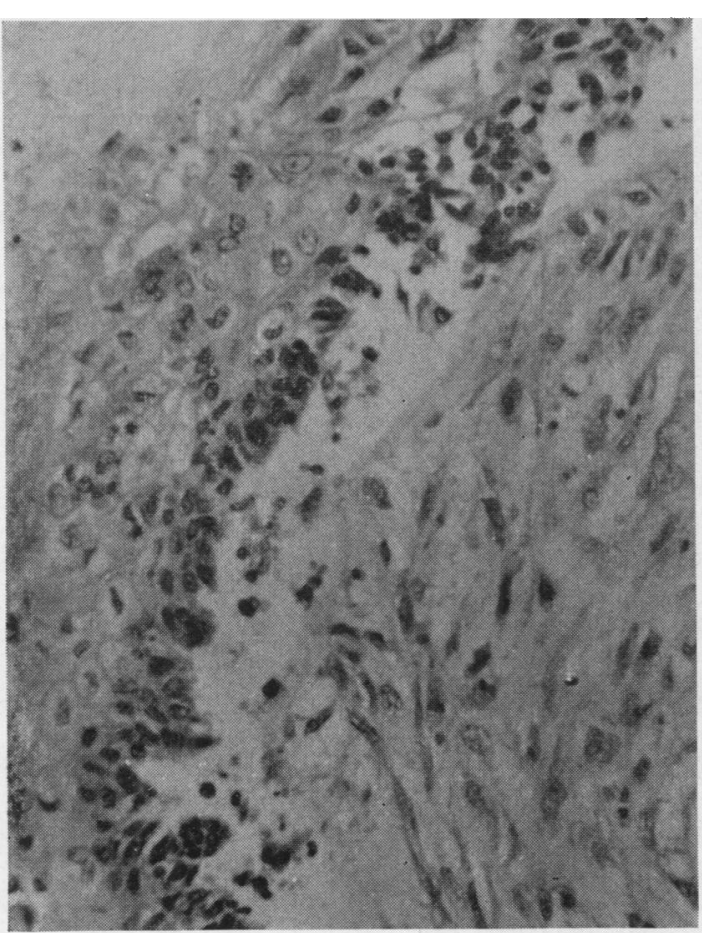

FIG. 3 .

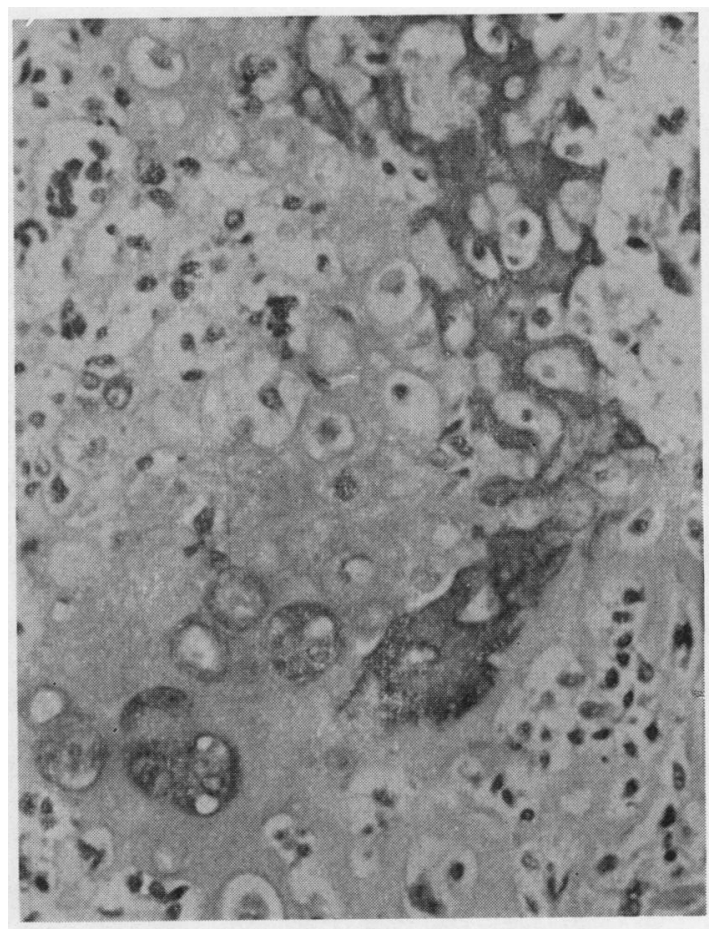

FIG. 5 .

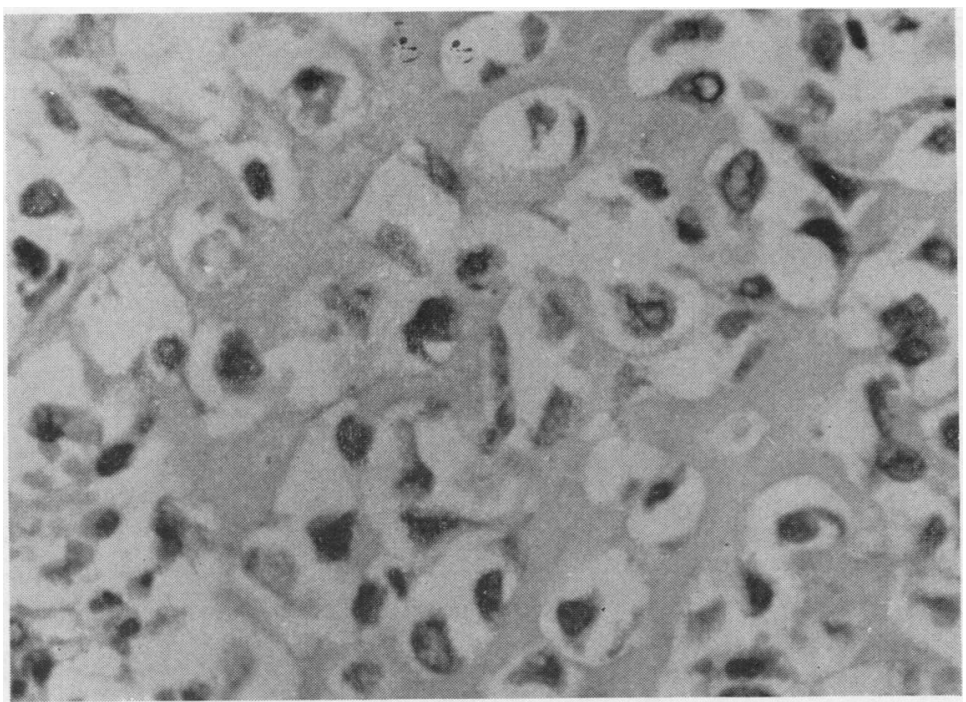

FIG. 3. Poorly differentiated carcinoma is present on the left and exuberant desmoplastic growth on the right. Haematoxylin and eosin $\times 200$.

FIG. 4. In this field the fibroblasts have large rounded nuclei and their fibrils are merged into an eosinophilic homogeneous matrix. Haematoxylin and eosin $\times 250$.

FIG. 5. Hyaline cartilage with central calcification lying within the loose immature stroma of the tumour. Haematoxylin and eosin $\times 200$.

FIG. 4 . 


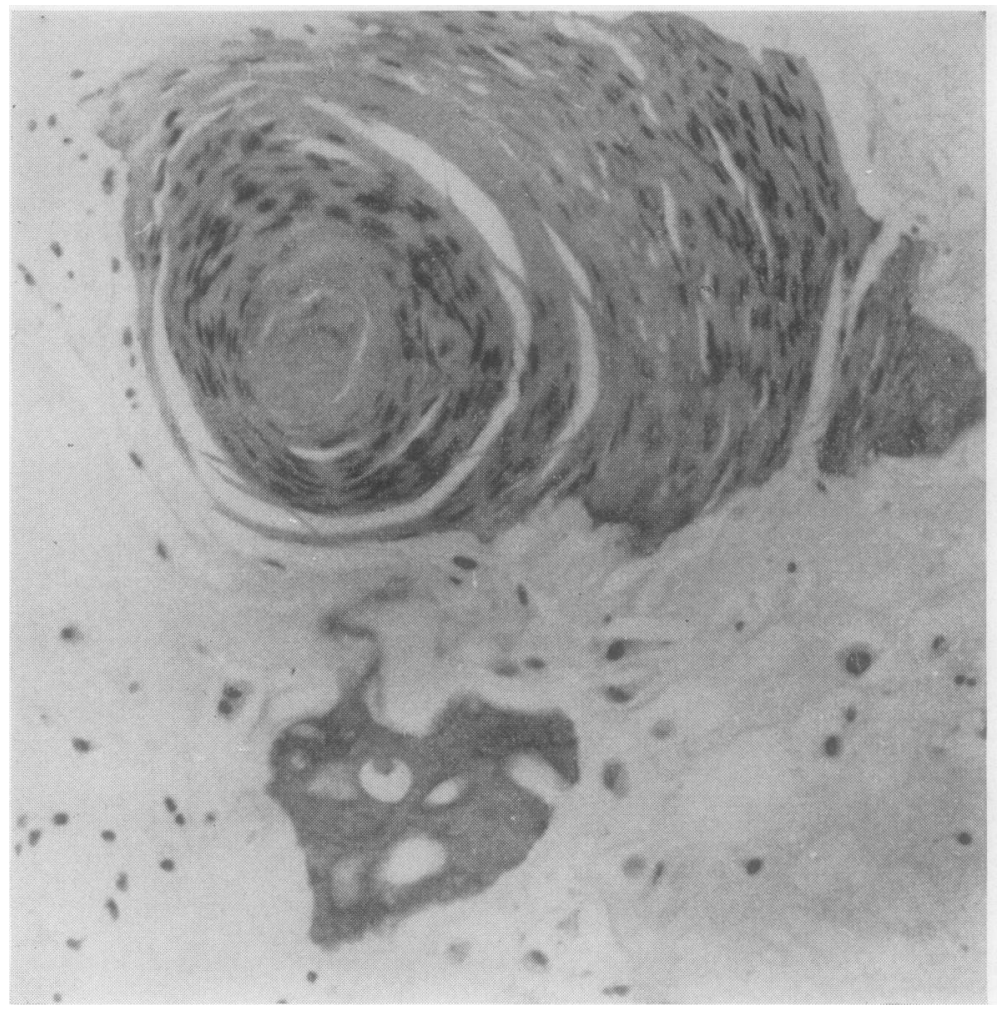

FIG. 6. A well-developed squamouso pearl lies within a matrix of cartilage. There is a darker-staining focus of calcification in the cartilage. Haematoxylin and eosin $\times 125$.

Cartilaginous zones were well defined with only single nuclei within the clefts (Fig. 6). Bony trabeculae were occasionally lined by well-orientated osteoblasts.

No other types of tissue were present in the tumour. The more undifferentiated portions of the tumour appeared identical to the biopsy specimen.

Most of the tumour was a mass of necrotic debris with some calcified branching trabeculae of woven bone. A peribronchial lymph node was invaded by squamous cell carcinoma and contained fragments of mature cartilage. The tumour was interpreted as a squamous cell carcinoma with a desmoplastic osteocartilaginous stroma.

The lung contained areas of chronic pneumonitis and focal acute pneumonitis. Multiple sections of both testes showed no spermatogenesis and no tumour.

\section{DISCUSSION}

The clinical features and necropsy findings in this case are those of carcinoma of the lung. The areas of carcinoma with cornification and squamous pearls found in the more mature stroma suggest some response to radiation.
The crux of this case is the interpretation of the gross and microscopic appearances of the tumour as a squamous carcinoma with osteocartilaginouso stroma. This has not previously been recognized. The evidence upon which this interpretation is based? is as follows:

The differentiation of the fibrous stroma in this tumour is identical with the normal process of intramembranous ossification and cartilage formation, which has recently been clarified (Collins and Curran, 1959).

Osteocartilaginous metaplasia developing by this process may occur in sites far from skeletal bone in N association with various pathological stimuli, including the experimental transplantation of normal epithelium as well as tumour.

It is probable that bone itself is not important in? extraskeletal osteogenesis even although the se- $c$ ? quence of changes leading to osteogenesis is the same, no matter what the site (Curran and Collins, 1957). Indeed, attempts to induce ossification in extraskeletal sites in animals by injection of bone $\frac{\overrightarrow{\mathrm{D}}}{\mathrm{C}}$ extracts or cartilage have been unsuccessful, while the same techniques using bladder epithelium haveo resulted in ossification (Constance, 1954; Loewi, 1954). Transplants of rat liver carcinoma have also 0 
resulted in osteocartilaginous stromal metaplasia, even when this was absent from the primary tumour (Paget, Walpole, and Ashton, 1958). As early as 1933, Huggins and Sammet had produced ossification in extraskeletal sites by transplantation of ga'l bladder epithelium and observed that when ossification occurs, calcification need not necessarily follow. Osteocartilaginous stroma similar to that present in this tumour has been described in a variety of tumours, mainly adenocarcinomata. Adenocarcinoma with osseous metaplasia of the appendix (one case), stomach (two cases), and rectum or rectosigmoid (11 cases) was reviewed by Engel and Dockerty (1962). Pang (1958) reported four urinary bladder tumours with osseous or cartilaginnus metaplasia. Ossification in a variety of rare a nd unusual tumours has been reported by Scheide, rger (i939), Hochberg, Grayzel, Berson, and Rosenterg (1949), and Llombart and Gomar-Guarner (1962). Van Patter and Whittick (1955) recorded ossification in the stroma of a pulmonary metastasis from a restal carcinoma with stromal ossification.

The remarkable desmoplastic response occasionally seen in breast adenocarcinoma with chondroid and osteoid features, even to the point of cytological resemblance to osteogenic sarcoma, is well known. In this situation there are often areas growing as squamous cell carcinoma (Stewart, 1950). An instance of the development of this iesion in a fibroadenoma is illustrated by the second ca: $\geq$ of Robb and MacFarlane (1958).

The matrix of the cartilaginous and occasionally osseous metaplasia in pleomorphic salivary adenomata contains connective tissue acid mucopolysaccharides (Yates and Paget, 1952) which is the product of the intercalated duct myo-epithelium (Azzopardi and Smith, 1959). In this tumour the origin of the acid mucopolysaccharide necessary for the transformation of the osteogenic field into chondroid tissue is apparent.

The histological features in this tumour differentiate it from a number of other lung and mediastinal tumours with which some confusion might occur.

Mediastinal teratoma most often, if not always, arises in the thymus (Inada and Nakano, 1958). In this present case, the origin of the tumour was the left main bronchus; there was no thymus tissue in the 20 sections of the tumour studied. No tissue other than the squamous cell carcinoma and its stroma was found. Multiple sections of the testis contained no tumour. The appearances and behaviour of the tumour were entirely unlike those of bronchial hamartoma or the curious encapsulated non-metastasizing tumour reported by Simon and Ballon (1947).

Carcinosarcoma is a disputed entity. The bony and other sarcomatoid features in tumours other than those of the lung are considered to be stromal reaction induced by the carcinoma (Willis, 1960). There have been certain endotracheal and endobronchial tumours in which it is difficult to dispute the diagnosis of carcinosarcoma, except for the absence of independent sarcomatous metastases (Bergmann, Ackerman, and Kemler, 1951; Taylor and Rae, 1953; Drury and Stirland, 1959). As far as the present tumour is concerned, the possibility of a 'carcinosarcoma' is ruled out by the absence of the criteria of malignancy in the stroma. None of the fibrous, osteoid, or chondroid components displayed giant cells, cellular or nuclear pleomorphism, abnormal mitotic figures, or invasion of vessels.

The views expressed herein do not necessarily coincide with those of the Surgeon General, U.S.A.F. The authors wish to thank Air Commodore W. P. Stamm for his advice and the Director General of Medical Services, Royal Air Force, for permission to publish.

\section{REFERENCES}

Azzopardi, J. G., and Smith, O. D. (1959). J. Path. Bact., 77, 131. Bergmann, M., Ackerman, L. V., and Kemler, R. L. (1951). Cancer (Philad.), 4, 919.

Collins, D. H., and Curran, R. C. (1959). In Modern Trends in Pathology, edited by D. H. Collins, p. 300 . London, Butterworth. Constance, T. J. (1954). J. Path. Bact., 68, 381.

Curran, R. C., and Collins, D. H. (1957). Ibid., 74, 207

Drury, R. A. B., and Stirland, R. M. (1959). Ibid., 77, 543.

Engel, S., and Dockerty, M. B. (1962). J. Amer. med. Ass., 179, 347.

Hochberg, L. A., Grayzel, D., Berson, S. L., and Rosenberg, S. (1949). Arch. Surg., 59, 166.

Huggins, C. B., and Sammet, J. F. (1933). J. exp. Med., 58, 393.

Inada, K. and Nakano, A. (1958). Arch. Path., 66, 183.

Loewi, G. (1954). J. Path. Bact., 68, 419.

Llombart, A. Jr., and Gomar Guarner, F. (1962). Rev. clin. esp., 85, 283.

Pang, L. S. C. (1958). J. Path. Bact., 76, 357.

Paget, G. E., Walpole, A. L., and Ashton, S. (1958). Ibid., 75, 357.

Robb, P. M., and MacFarlane, A (1958). Ibid., 75, 293.

Scheidegger, S. (1939). Schweiz. Z. Path., $2,153$.

Simon, M. A., and Ballon, H. C. (1947). J. thorac. Surg., 16, 379.

Stewart, F. W. (1950). Tumors of the Breast (Atlas of Tumor Pathology, Sect. IX, Fasc. 34), p. 66. Armed Forces Institute of Pathology, Washington.

Taylor, H. E., and Rae, M. V. (1953). J. thorac. Surg., 24, 93

Van Patter, H. T., and Whittick, J. W. (1955). Amer. J. Path., $31,73$.

Willis, R. A. (1960). Pathology of Tumours, 3rd ed., p. 140. Butterworth, London,

Yates, P. O., and Paget, G. E.(1952). J. Path. Bact., 64, 881. 